\title{
Correction to: Leadership for Instructional Uncertainty \\ Management: Revisiting School \\ Leadership in South Korea's Context of Educational Reform
}

Seung-Hwan Ham, Byeong Chan Kim and Wang Jun Kim

\section{Correction to:}

Chapter 9 in: S. Hairon and J. W. P. Goh (eds.),

Perspectives on School Leadership in Asia Pacific Contexts, https://doi.org/10.1007/978-981-32-9160-7_9

The original version of the chapter was published without the acknowledgement.

This has now been corrected. 